\title{
Issues Relating to Development and Management of Social Sector in the Digital Age
}

\author{
Lvova M.I.* Shvedov V.V. Sulimin V.V.
}

\author{
Ural State University of Economics, Yekaterinburg, Russia \\ *Corresponding author.Email: lvova_usue@mail.ru
}

\begin{abstract}
The article is devoted to the issues of social management in the conditions of modern production and economic transformations. The main purpose of the study is to analyze the social aspects of scientific management for those types of work that cannot be regulated by the quantitative system of labor standards. Within achievement of the specified purpose a number of tasks are solved, methodological problems of scientific management by information work are defined; the algorithm of administrative influence according to specifics of social management is offered; the expediency of introduction of scientific social management is proved. As research methods used: dialectical method-to assess the feasibility of applying quantitative labor standards to the management of intellectual labor; methods of historical analysis to find tools to modernize the scientific school of labor rationing; methods of systematic and comparative analysis to assess the possibility of using classical developments in scientific management to solve managerial problems of modern enterprises. Induction method in the development of the author's concept of scientific management using methods of social impact.
\end{abstract}

Keywords: management, functions, social norms, efficiency, social requirements, goals

\section{INTRODUCTION}

The urgency of the problem of social management is considered in two aspects. On the one hand, in the context of crisis processes, the use of economic management methods is not always possible or appropriate. Moreover, social management, under certain conditions, proves to be a more dynamic way of changing the behavior of employees, which makes this method effective in conditions of limited time for managerial influence. On the other hand, modern domestic management practices do not yet sufficiently use the possibilities of social management, which is due to the reluctance of most organizations to implement a set of mechanisms of social impact in practice. An important limitation of the use of social management methods is the change in the character of the modern labor process.

This change is associated with an increasing volume of intellectual work, which significantly reduces the possibility of using classical control techniques associated with the classical system of scientific management. Thus, the aim of the study is to analyze the social aspects of scientific management for those types of work that cannot be regulated by the quantitative system of labor standards. In order to achieve this goal, it is necessary to solve a number of tasks: to determine the methodological problems of scientific management of information work; to propose an algorithm of management impact in accordance with the specifics of social management; to justify the feasibility of the proposed changes.

\section{MATERIAL AND METHODS}

As methods of research we used general scientific methods of cognition. In particular, the dialectical method is used to assess the feasibility of applying quantitative labor standards to the management of intellectual labor. Methods of historical analysis to search for tools of modernization of the classical scientific school of labor rationing. The methods of system and comparative analysis were used to assess the possibility of using classical developments in scientific management to solve managerial problems of a modern enterprise. Induction method in the development of the author's concept of scientific social management [1].

In the course of assessing the current state of scientific management, it is determined that social management is an objectively necessary form of managerial influence, which ensures consistency and order in the achievement of socially significant goals and solving collective problems through the joint activities of a group of persons (including a decentralized group). As a result of the analysis of scientific literature it is established that the majority of theoretical and applied researches are focused on social management in the conditions of big social groups, as a rule, institutionalized (collective of the enterprise, the population of the territory).

At the same time, the issues of social management in small groups (which are, for example, teams, project groups) are based mainly on the classical methods of material motivation and technical rationing of labor. As the reasons 
we see the fact that the system of social management requires a sufficiently qualified subject of management. The second fact is the absence of specific universal methodological recommendations on the social management of small labour groups.

For application of classical methods of management and regulation of work, in modern work process there are a number of restrictions among which: firstly, - its result is difficult to formalize (it is difficult to define concrete result of work) in the conditions of information intellectual work; secondly, - result of work can appear a little predicted and dependent on external conditions (in which the labor process occurs directly). It should also be noted that the results of intellectual work are largely derived from the social norms and values of the social environment in which work takes place. In other words, each participant in the labor process can have a unique personal experience, different social norms and values, which provides different labor results and a different assessment of these results. External (evaluation by managers) and internal evaluation (by the employee) of labor results may not match. And if in the working conditions of operator character-such discrepancy can be neglected, in the conditions of creative work - it can directly affect its result. It is also important from the point of view of social management and the rationing of labour that any work is cyclical.

The speed of gaining experience (professional, social) will depending on the length of the cycle, which should also be taken into account in the framework of social management. We believe that the last point deserves special attention [2]. The duration and character of the work cycle of an individual employee, depending on the characteristics of his professional functions, can vary significantly in duration. Thus, the duration of the work cycle of the chief accountant, in our opinion, is 1 year, since it contains work related to the preparation of the annual report (periodicity of which is 1 year). At the same time, the work of the call center operator who provides telephone counseling to clients is repeated 100 times or more in the individual cases.

Accordingly, the individual labor cycle of the operator will be more rapid than the accountant. On the one hand, this causes a faster acquisition of experience (professional, communicative, social), and on the other - forms a faster increase in fatigue due to a constant repetition of the work cycle (monotony, a possible sense of low social significance of labor). It should be taken into account that information labor experience is formed in the process of social communication (relations), however, during the labor cycle, the operator has a standardized character of relations, which leads to low significance of his individual labor cycle.

On the other hand, the problem of drafting an annual report relates to the chief accountant, other types of reports can be prepared by a regular accountant, from which the cycle of the work of a particular accountant will be longer, and the cycle time will be shorter (with a corresponding decrease in the social content of the corresponding cycle). In this case, both for the operator and for the chief accountant, the structure of the work cycle consists of separate microcycles (also differ in duration depending on the specific labor function).

In our opinion, fatigue does not always occur as a result of the performance of a certain type of work, but often as a result of its constant repetition, which can be inherent in social and professional experience. Therefore, what has been said above is an important methodological problem that needs to be addressed within the framework of the social management of intellectual labor [3].

\section{RESULTS AND DISCUSSION}

In our opinion, it is expedient to use the duration of individual work cycles (to set the normative duration of operations) as a kind of norm for the use in rationing of intellectual labor. This indicator creates prerequisites not only for the planning and assessment of work but can act as a means of regulating the accumulated fatigue and enrichment of social experience (indicator of social competence of the employee). The importance of such index is determined by the fact that informational labour significantly increases the role of the individual, which is why there is a need of personalization (adaptation to the value-motivational orientations of the individual) used labour standards (establishing standards of social content). Such personification can be achieved by analyzing the social causes of individual efficiency (motives of individual labor behavior)

These reasons largely determine the conditions and limits of realization of the accumulated experience of information work, which directly affects social relations in the labor group and determines the social efficiency of the labor process as a whole. In the context of modern transformations, as the Ukrainian researcher V. E. Pilipenko notes, the labor behavior of workers comes to the fore... [4]. Since labour behaviour is a form of social behaviour, it is based on labour norms and values that are internalized by the individual in the course of work interaction in a particular work group. Thus, understanding (accounting) of social and labor norms in the process of social management acquires a significant degree of importance. Understanding (accounting) of social and labor norms is defined by us as typical models of behavior of individuals in standard social situations, predetermined by their subconscious choice.

Taking into account the fact that depending on the character of the professional activity of the norms will be different, there may be a problem of coordination of specific labor standards of individual groups interacting in the work process. Since the above-mentioned processes have a fundamental impact on the regulation of labor behavior and the acquisition of social experience of employees, there is a need to implement all management functions (planning, organization, motivation and control) in relation to them. It should be borne in mind that in the framework of the labor collective system of norms and values is relatively dynamic, respectively, there is a need 
for its preliminary study (before the beginning of the managerial impact).

There is also a link between the social norms of individual members of the working group and the social norms that dominate the group (since not all group norms will necessarily be dealt by all members of the group). Based on the increasing role of individual labor due to the growth of its creative nature, there is a need for external regulation of labor practices, as well as the establishment of limits of their self-regulation.

The aim is to create social conditions in which the labor actions of employees correlate as much as possible with the expectations of employers (goals of the organization). In the conditions of stationary workplaces similar influence can be provided at the expense of stimulation of workers (in the presence of external control).

However, in the conditions of individualized information (intellectual) work (freelance, remote jobs) there is a problem of finding mechanisms of influence on the individual normative field of the employee. In this context, by means of scientific management, we propose to consider, on the one hand, the self-correction, and on the other, the active Declaration of desired practices, with the aim of their "integration" into the system of individual life values (social norms) of individual workers. As objectifying parameters of information labor, we are invited to consider the socially expected result of labor, characterizing the entire work process, as well as the intensity of the work cycles [11]. The algorithm of action in this case will be the following: "the establishment of a social norm - the workers' awareness of this norm - the individual's realization of his own value orientations in order to achieve success in the group - a comparison of the ideas of maximizing one's own effectiveness with the existing (declared) value-normative base." The absence of a declared norm can lead to the fact that optimizing one's own effectiveness to enter into a certain dissonance with the value orientations of other members of the collective. Such an approach, in our opinion, will cause conflict (in A. Zdravomyslov's classification - a conflict at the level of everyday life) because such conflicts are associated with the use of new opportunities for self-affirmation by people, with complex processes of adaptation to values, norms and requirements formulated for the first time [5].

Consequently, the establishment of a social norm (intensity, effectiveness, importance) of labor is an important component of scientific management in the face of growing information labor. In this case, we are talking about the norm-orientation. However, having established the norm, it is necessary to give the workers a mechanism (toolkit) to achieve such a norm. One of such mechanisms can be the creation of a system of self-regulation (the formation of the skills of such activities among employees). For persons of intellectual work, selfregulation is mostly represented by time management. Classical standardization of labor is aimed at managing the efficiency of the labor process of a group of average performers, with the aim of increasing its overall efficiency. Information (intellectual) labor, due to their specificity's, makes the scientific school of classical labor standardization unsuitable for solving specific managerial tasks. Because of this, there is a need to adapt the ideas of time management to the standardization of labor of these types. Speaking about the role of the individual in the labor process, it should be noted that in fact, it is about improving the efficiency of the collective's functioning, by implementing individual egoistic aspirations to maximum individual productivity. In the event that such an aspiration is available to all participants of the group, a consensus is possible.

However, in the presence of contradictions, a social conflict is inevitable. In this case, individual savings are possible in the conditions of a permanent change in the parameters of the organization of labor (which is impossible), or in conditions of general (group) time savings. The deepening of the modern division of labor, reduces practically to no the advisability of individual saving time. Accordingly, such savings should act as a group value. Therefore, for the successful implementation of the algorithm of management influence, there is a need for its management support at all stages. The process of establishing a social norm can be provided with means of social engineering influence, the process by which the individual realizes his own value orientations must be determined by internal organizational conditions. Comparison of ideas about maximizing one's own effectiveness should be supported by methods of institutional (external) evaluation, and, ideally, of social control.

\section{CONCLUSION}

Considering social management from the socioengineering positions, in fact, we are talking about changing social norms (values), causing a certain social behavior of the employee depending on the changes in the market situation of the enterprise. However, most modern theorists of the organization of work do not consider the individual in the process of work as a source of normsetting and consider possible only external rationing. In our view, this technocratic approach is fundamentally outdated. The social content of information work and the further individualization of values creates prerequisites for the search for alternative ways to improve their own results.

The key reference point is the achievement of the desired role (place) of the individual in the system of social relations. Depending on the specifics of the organization of labor as a "system" will be a team (for the subjects of collective labor) or society as a whole (for the subjects of creative labor). In most cases, the orientation on "towards society as a whole" forms the emergence of inflated social expectations. As a result of consideration of the first task of research the main problems of scientific management of information work were defined. As a result of the analysis insists that the modern system of scientific management has a number of differences from the system proposed in 


\section{REFERENCES}

effective management of information work requires fundamentally different approaches. The specified system must coordinate its goals with the goals and the state of the environment for maximum compliance with external parameters.

In the framework of the second task aimed at developing an algorithm of actions to ensure managerial influence within the system of organization and rationing of labor, we proposed the following algorithm: "establishing a social norm-awareness of employees of this normimplementation of the individual's own value orientations in order to achieve success in the group-comparison of ideas about maximizing their own efficiency with the existing (declared) value-normative base". As a norm, for use in the formation of intellectual labor, it is proposed to use the duration of individual labor cycles (normative intensity). As another social norm, an indicator of social performance based on the system of social expectations of an employee (his or her labor group) is proposed. As part of the solution of the third problem, it is shown that the practical implementation of the social aspects of scientific management ultimately boils down to the formation of a stable system of social norms and rules. At the same time, part of the norms (rules) should be resistant and regulate the General rules of joint employment, and the second part should be flexible enough. A flexible part of social norms should ensure changes in the regulatory system of the labor group, as a response to changes in the external environment of the organization. Thus, the managerial impact will consist of two parts: development and implementation of social norms; stimulation of the fastest assimilation of social norms by all members of the labor collective. Changes in the regulatory field should be the result of consistent implementation of all management functions (social planning, organization of social processes, motivation of the team and ensuring control of the changes).

The ultimate criterion of the effectiveness of such a process should be the consistency of social and labour norms of the individual (group) objectives of the organization, of which he is. For persons engaged in intellectual work, the main criterion will be to increase individual efficiency, including through the application of the principles of time management. For persons engaged in performing work-the maximum compliance with the preordered labor standards and values. Specific actions will be determined by the management model chosen in the organization, the type of organizational culture, as well as a number of other organizational factors. However, the actions of managers should be aimed at the formation of a system of social norms and values in the labor organization. Scientific management, respectively, will be determined by the degree of correspondence of artificially introduced social norms to the goals of the organization.
[1] Son, C., Sasangohar, F., Neville, T.J., Peres, S.C., Moon, J. (2020). Evaluation of work-as-done in information management of multidisciplinary incident management teams via Interaction Episode Analysis. Applied Ergonomics, 84, pp. 71-81

[2] Zhao, X. (2020). System test of party affairs work management information system in higher vocational colleges. Advances in Intelligent Systems and Computing, 1117 AISC, pp. 774-780.

[3] Jamil, S., Yukongdi, V. (2020). Information systems workforce and innovative work behavior: The role of participatory management, affective trust and guanxi. International Journal on Semantic Web and Information Systems, 16 (1), pp. 146-165.

[4] Schüffler, A.S., Thim, C., Haase, J., Gronau, N., Kluge, A. (2020). Information Processing in Work Environment 4.0 and the Beneficial Impact of Intentional Forgetting on Change Management. Zeitschrift fur Arbeits- und Organisationspsychologie, 64 (1), pp. 17-29.

[5] Suryagama, D., Satibi, Sumarni (2019). Influence between drug management information system, work behavior and drug management activities on organizational performance. (2019) Research Journal of Pharmacy and Technology, 12 (12), pp. 6013-6018.

[6] Cheng, Z. (2019). Linking error management atmosphere with service employee's thriving at work: A social information processing perspective. 2019 16th International Conference on Service Systems and Service Management, ICSSSM 2019, pp. 177-279.

[7] Eka Putra, F.P., Irwanto, T.J., Heryadi, A.Y. (2019). The design and implementation of management information system on student real work $(\mathrm{KKN})$ in Madura University. International Journal of Civil Engineering and Technology, 10 (2), pp. 159-175.

[8] Bernardi, R., Sarker, S., Sahay, S. (2019). The role of affordances in the deinstitutionalization of a dysfunctional health management information system in Kenya: An identity work perspective. MIS Quarterly: Management Information Systems, 43 (4), pp. 11771200 .

[9] Serrano, S.C., Avilés, R.A., Cuenca, G.M., Calvo, B.S. (2019). Orphan Works at Theatre Library and Information Centres: Assessing Librarians' Perceptions and Management in Spain. Journal of Academic Librarianship, 45 (1), pp. 58-65. 
Sharan, D., Rajkumar, J.S., Jose, J.A. (2019).

Effectiveness of Onsite Occupational Health Clinics in Management of Work Related Musculoskeletal Disorders in 12000 Information Technology Professionals. Advances in Intelligent Systems and Computing, 821, pp. 642-646.

[11] Bodrunov S. D. Noonomika: kontseptual'nye osnovy novoy paradigmy razvitiya [Noonomics: The conceptual basis of the new development paradigm]. Izvestiya Uralskogo gosudarstvennogo ekonomicheskogo universiteta $=$ Journal of the Ural State University of Economics, 2019, vol. 20, no. 1, pp. 5-12. DOI: 10.29141/2073-1019-2019-20-1-1. 